\title{
A RARE TYPE OF CONGENITAL CYANOTIC HEART DISEASE
}

\author{
BY \\ PATRICIA FERNANDO and M. V. F. PERERA \\ From the Department of Paediatrics, University of Ceylon, and the \\ Pathology Unit, Lady Ridgeway Hospital, Colombo
}

(RECEIVED FOR PUBLICATION DECEMBER 30, 1960)

A case of situs inversus with laevocardia and chamber inversion complicated by transposition and hypoplasia of the pulmonary artery and a patent ductus is published because of the rarity and complexity of this type of case. Advances in anaesthesiology and cardiac surgery demand that every case of congenital heart disease be subject to careful diagnostic appraisal in order that corrective surgery be effected where this is indicated. Where all the modern investigatory methods are available most of the congenital cardiac anomalies can be unravelled, but even under these circumstances a few bizarre anomalies defy accurate antemortem or pre-thoracotomy diagnosis. Unfortunately, our case died of intracranial abscess before we were able to complete even those investigations available to us, such as cardiac catheterization and blood gas analysis. Hence we had not reached a definite diagnosis when the patient came to autopsy.

\section{Case Report}

The patient, S.N., was a 9-year-old girl, who was admitted to the Children's Hospital, Colombo, on December 17, 1959, for fever of one week's duration, accompanied by vomiting during the latter five days. The fever had been heralded by chills and was intermittent. She did not complain of a headache, nor were there other clues in the history of this illness to suggest a diagnosis of a cerebral abscess. The parents' attention had been drawn to the child's cardiac anomaly by the school medical officer. They had not noticed cyanosis in early infancy. She had been admitted to the children's hospital five years previously for chest pain, but no further information about this illness could be obtained.

On examination, her nutrition was considered consistent with the low socio-economic status of her family, and her general condition was good. She was found to have clubbing of fingers and toes and central cyanosis.

No abnormalities were detected in the respiratory system.

The pulse rate was 98 per minute, the rhythm was regular and the volume and tension were good. Her blood pressure was $110 / 80 \mathrm{~mm}$. $/ \mathrm{Hg}$ in each arm. The apex beat which was palpated in the fifth interspace in the left mid-clavicular line was left ventricular in type. No thrills were felt and there was no parasternal heave. A grade 3 systolic murmur was heard best at the base and was conducted to the clavicles. It was also heard at the third left interspace. The pulmonary second sound was soft and single.

Radiologically the heart was found to be moderately enlarged with predominant enlargement of the right ventricle. Screening was not done as the radiology department was under repairs. However, the posteroanterior view revealed oligaemia of the left lung field, with normal to increased vascularity of the right lung field (Fig. 1).

The electrocardiogram showed biventricular enlargement, the left being the dominant chamber (Fig. 2). No definite diagnosis was made about the condition for which admission was sought but, as her symptoms were relieved by the penicillin which was prescribed for her and because of the pressure for beds, she was discharged with advice to report back on January 2, 1960, so that her case could be discussed at the Cardiology Conference scheduled for January 5, of that year, when further cardiological investigations would be arranged.

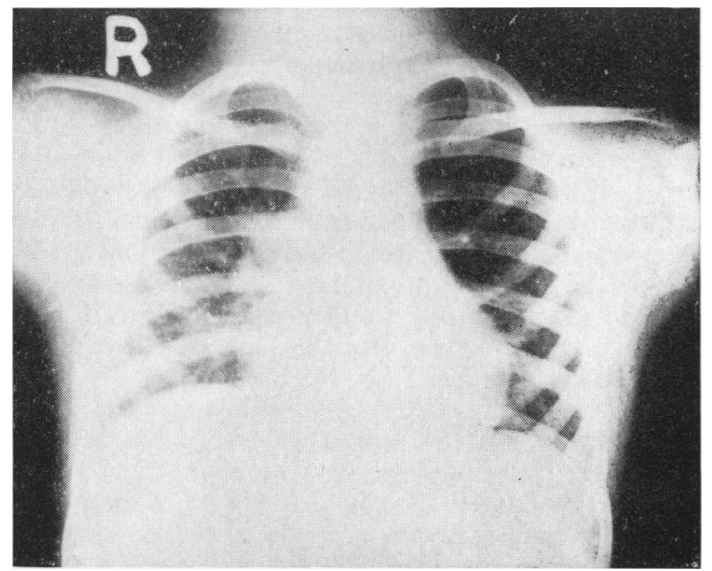

Fig. 1.-Postero-anterior teleradiograph. 


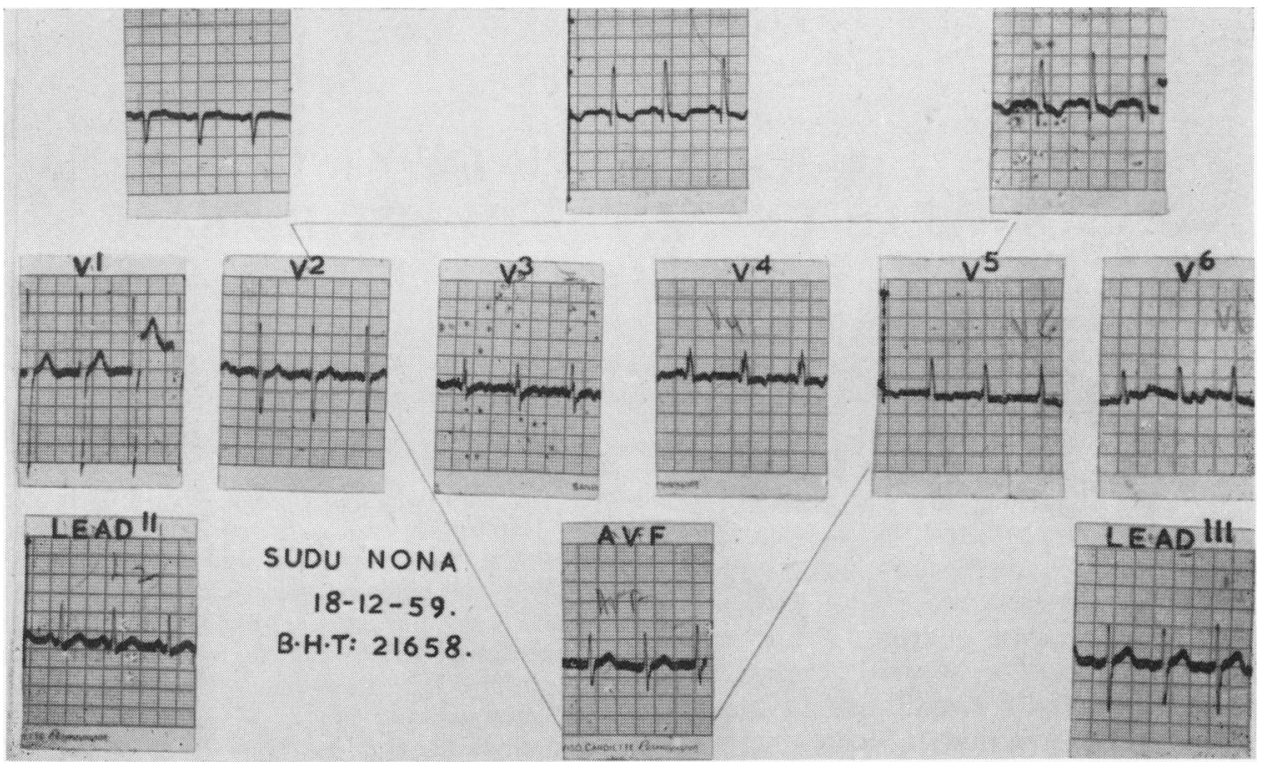

FIG. 2.-Electrocardiogram showing biventricular enlargement.

We were only able to say that she had bizarre anomalies of which we had spotted only the ventriculo-septal defect, pulmonary stenosis and hypoplasia of the left pulmonary artery. The cause of the cyanosis was still an enigma.

However, due to recurrence of vomiting severe enough to cause anuria and severe headache, she was readmitted on December 26, 1959.

On examination, we found a drowsy child who on being roused was very uncooperative. The cardiac findings were in status quo except for the pulse which was noted to be slow and bounding, leading to a suspicion of increased intracranial pressure. This was confirmed by the presence of bilateral papilloedema. We also noted marked pulsatile distension of the leftsided neck veins and this made us suspect a superior vena cava opening into the left atrium and thus accounting for the cyanosis. We made a tentative diagnosis of brain abscess, and treated her with pencillin and streptomycin in adequate dosage and with measures to reduce intracranial tension. Neurological examination carried out a few days later, when her mental condition permitted, pointed to a lesion in the posterior cranial fossa, i.e. bilateral extensor plantar reflexes and a tendency of the right arm to fall away to the same side.

An appointment for an electroencephalogram was made after consultation with the Neurologist, General Hospital, Colombo.

The parents removed the child against medical advice on January 16. At the time of discharge she had only minimal neurological symptoms or signs.

She was readmitted for the last time on February 16, with the same symptoms as on the previous occasion. She had marked papilloedema and her blood pressure had gone up to $130 / 95 \mathrm{~mm} . / \mathrm{Hg}$. Hence she was put back on the previous therapeutic regime. A consultation with the Neurosurgeon, General Hospital, Colombo, was made and a transfer to the neurosurgical ward was advised. However, she died quite suddenly that night.

An autopsy was performed next morning and a rightsided cerebellar abscess was found (Fig. 3). It contained

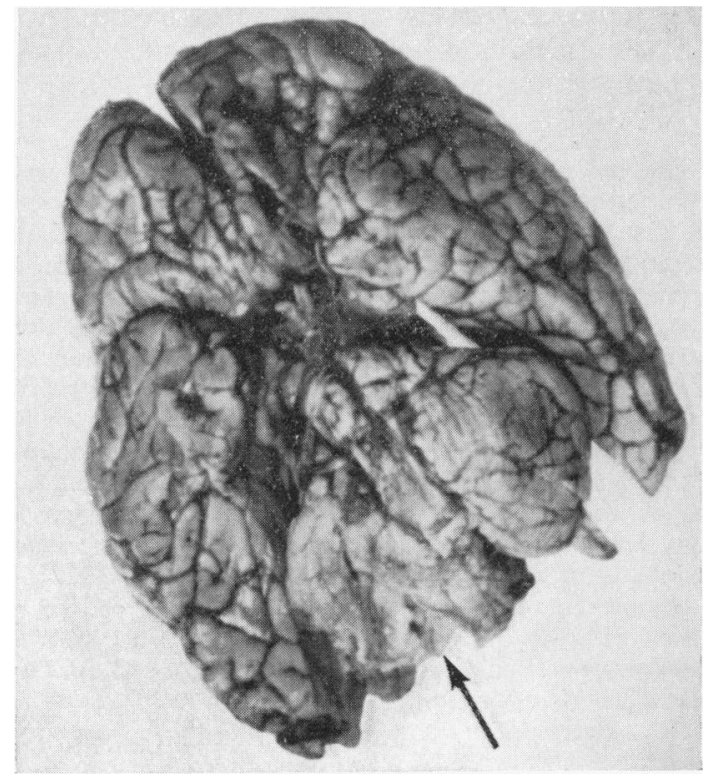

Fig. 3.-Ventral surface of brain showing abscess of right cerebellar hemisphere. 


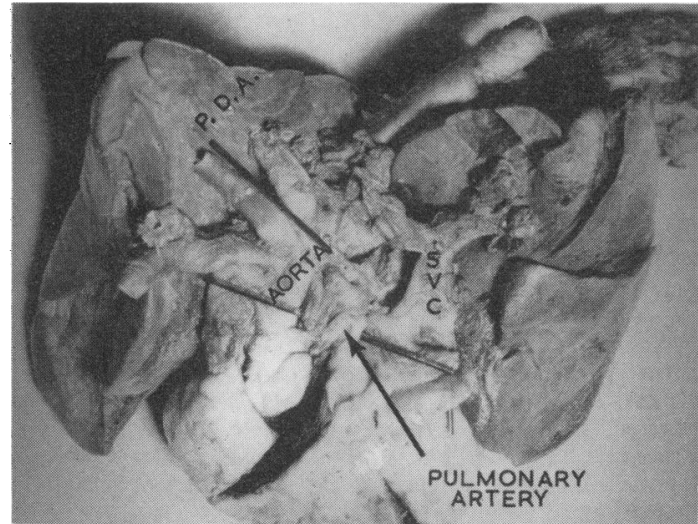

FIG. 4.-Anterior view of heart showing patent ductus arteriosus between aorta and left pulmonary artery, the left-sided superior vena cava and the transposition and hypoplasia of the pulmonary artery.

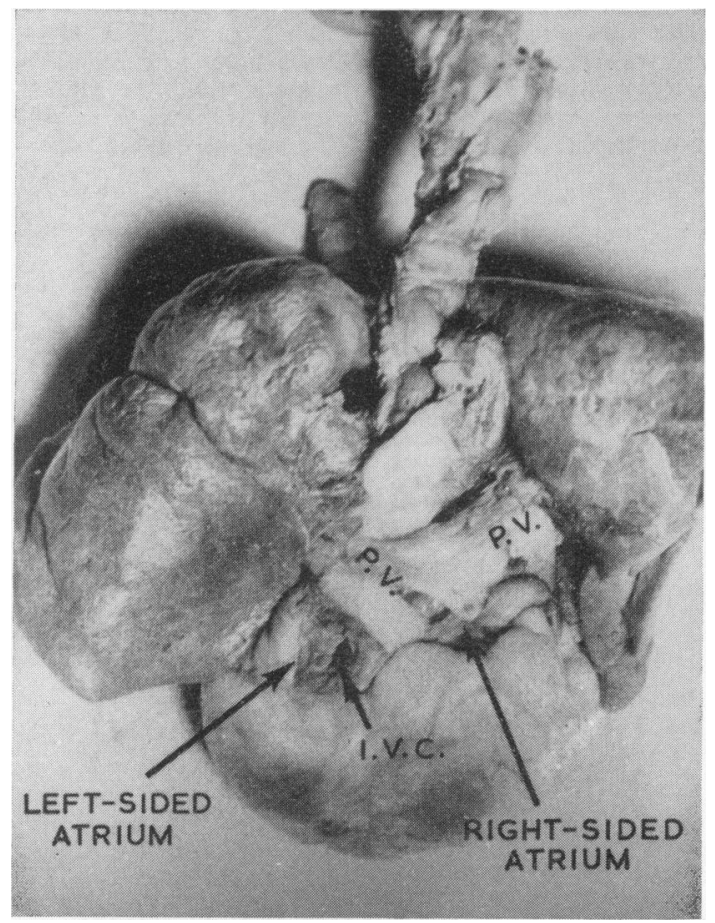

FIG. 5.-Posterior view of heart showing pulmonary veins [PV] opening into right-sided atrium and the opening of the inferior vena cava.

greenish yellow pus. There was a left-sided superior vena cava with gross enlargement of the right innominate vein as it crossed over and also definite dilatation of the left internal and external jugular veins. The heart was squarish in outline with the interventricular groove about midway (Figs. 4 and 5).

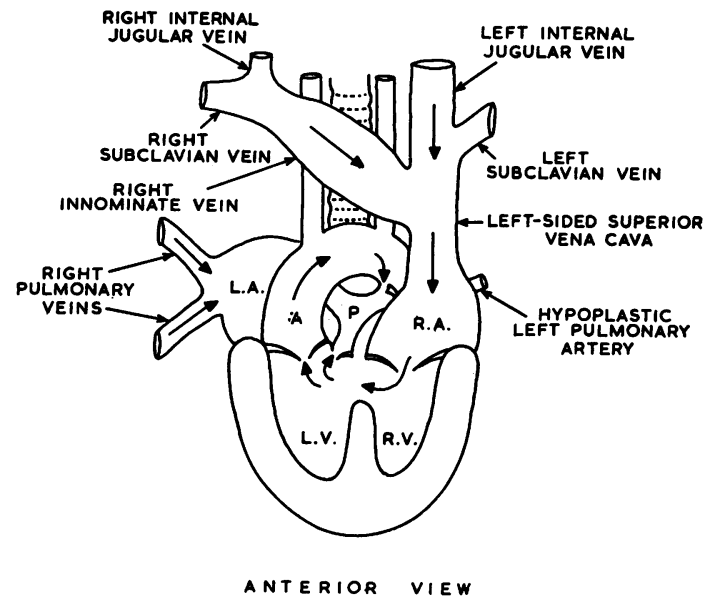

FIG. 6.-Diagrammatic representation of the cardiovascular anomalies.

The aorta and a small pulmonary artery were seen to arise from the right-sided ventricle, which communicated above with an auricle receiving all the pulmonary veins. A tricuspid valve separated these two chambers.

Situs inversus of lungs and abdominal viscera, not suspected during life, was found.

The inferior vena cava and the left-sided superior vena cava opened into the auricle on the left side, which was thus functionally a right auricle. However, this opened into a ventricle with muscular walls, the valve between these two chambers consisting of two long cusps and thus resembling the mitral valve. A large vessel did not arise from this ventricle, but there was a high septal defect between the two ventricles, the small pulmonary artery being immediately to the right of the septal defect. The left-sided ventricular wall was slightly thicker than the right-sided one, $12 \mathrm{~mm}$. and $10 \mathrm{~mm}$. respectively.

There was a hypoplastic left pulmonary artery as suspected during life from the radiologically evident oligaemia of the left lung field. A small patent ductus arteriosus was found between it and the aorta beyond the origin of the left subclavian artery. Fig. 6 is a diagrammatic representation of all the anomalies found. The cardiac chambers have been labelled according to their functional status and not according to the position in the body.

\section{Discussion}

According to Taussig (1947) situs inversus of the abdominal viscera with the heart occupying its normal position means that there has been complete reversal of all the organs and that the heart has been rotated back to the left. Such a condition is described as situs inversus with laevocardia. By laevocardia is meant that the heart is in the left hemithorax with the apex pointing to the left. She states that complicated cardiac anomalies 
accompany situs inversus with laevocardia, and that accurate clinical diagnosis is extremely difficult. Nadas (1957) is in agreement with her and adds that asplenia may further complicate the picture.

Incidence. Keith, Rowe and Vlad (1958) estimate the frequency as approximately one-tenth that of situs inversus with dextrocardia which has been found in approximately one in 10,000 (Torgersen, 1949, 1950; Lowe and McKeown, 1954).

Campbell and Forgacs (1953) in reporting 14 of their own cases had found 19 more in the medical literature. Nadas mentions that 11 cases were encountered amongst cardiology cases at the Children's Medical Centre in Boston in the 10 years preceding the publication of his book, Pediatric Cardiology.

Pathogenesis. According to Forgacs (1947) it is the change in relation between the liver and the heart that is responsible for the venous drainage into the left rather than the right side of the heart and for the consequent abnormalities in septation and the development of the cono-truncus structures.

The insult responsible for this type of developmental abnormality probably occurs between the third and fourth embryonic weeks.

In our case the ventricular division is not only incomplete, but the division of the bulbus cordis into aorta and pulmonary artery has been unequal, resulting in a small pulmonary artery which, in addition, is transposed and arises from the same chamber as the aorta.

Circulatory Dynamics. The venous return from the upper and lower parts of the body which reaches the left-sided ventricle can leave it only through the septal defect and gains the arterial chamber where admixture occurs. Most of this mixed blood leaves this chamber via the aorta. Most of the blood reaching the small pulmonary artery reaches the right lung, the left lung receiving blood via the small patent ductus which connects the aorta and the left pulmonary artery. The entire venous return from the lungs reaches the functional left auricle.

We are grateful to Professor C. C. de Silva, under whose care this case was admitted, for permission to publish this case, and to Mr. A. T. S. Paul, Thoracic Surgeon, Dr. G. Ratnavale and Mr. S. A. Cabraal, Consultant Neurologist and Neurosurgeon, General Hospital, Colombo, respectively, for interest shown in this patient.

We are also deeply indebted to Drs. R. E. Bonham Carter and Martin Bodian of The Hospital for Sick Children, Great Ormond Street, London, who very kindly gave an opinion on the interpretation of the clinical and autopsy findings as depicted in our notes, radiographs, electrocardiogram and photographs.

We also extend our thanks to Dr. D. T. D. Bulugahapitiya, Research Assistant, Department of Paediatrics, for help given in the care of this patient, and to Messrs. P. D. S. Amarasekera and A. S. Mahawatte of the Photographic Department, University of Ceylon.

\section{REFERENCES}

Campbell, M. and Forgacs, P. (1953). Laevocardia with transposition of the abdominal viscera. Brit. Heart J., 15, 401.

Forgacs, P. (1947). Congenital heart disease with isolated inversion of the abdominal viscera. Ibid., 9, 27.

Keith, J. D., Rowe, R. D. and Vlad, P. (1958). Heart Disease in Infancy and Childhood, p. 557. Macmillan, New York.

Lowe, C. R. and McKeown, T. (1954). An investigation of dextrocardia with and without transposition of abdominal viscera, with a report of a case in one monozygotic twin. Ann. Eugen. (Lond.), 18, 267.

Nadas, A. S. (1957). Pediatric Cardiology, p. 532. Saunders, Philadelphia and London.

Taussig, H. B. (1947). Congenital Malformations of the Heart, p. 513. The Commonwealth Fund, New York.

Torgersen, J. (1949). Genic factors in visceral asymmetry and in the development and pathologic changes of lungs, heart and abdominal organs. Arch. Path. (Chicago), 47, 566.

(1950). Situs inversus, asymmetry, and twinning. Amer. J. hum. Genet., 2, 361. 